\title{
Rancang Bangun Sistem Palang Otomatis Dengan Pengenalan Plat Kendaraan
}

\author{
Rahmat Darmawan ${ }^{1}$, Ahmad Taqwa ${ }^{2}$, dan Jon Endri ${ }^{3}$ \\ ${ }^{1}$ Politeknik Negeri Sriwijaya, Teknik Elektro, ${ }^{2}$ Politeknik Negeri Sriwijaya, Teknik Elektro \\ ${ }^{3}$ Politeknik Negeri Sriwijaya, Teknik Elektro \\ rahmat4darmawan@gmail.com,tommy@polsri.ac.id,jon_endri@polsri.ac.id
}

Coprespondent Author : Rahmat Darmawan

\begin{abstract}
- due to the increased use of parking lots and limited land, parking lots are often not used properly. However, this problem can be overcome by implementing an automatic crossbar system by detecting a raspberry pi based vehicle number plate. The vehicle number plate recognition process is carried out using the optical character recognition (ocr) method. The results of this final project will display the plate that has been detected and responds to the output provided.
\end{abstract}

Keyword - Motor Servo, Optical Character Recognition, Plate Recognition, Raspberry Pi.

Abstrak - dikarenakan meningkatnya penggunaan lahan parkir dan keterbatasan lahan, maka seringkali lahan parkir tidak digunakan secara tepat. Namun masalah tersebut dapat diatasi dengan cara mengimplementasikan sistem palang otomatis dengan pendeteksian plat nomor kendaraan berbasis raspberry pi. Proses pengenalan plat nomor kendaraan dilakukan dengan metode optical character recognition (ocr). Hasil pada tugas akhir ini akan menampilkan plat yang telah terdeteksi dan merespon ke output yang disediakan.

Kata kunci - Motor Servo, Optical Character Recognition, Pengenalan Plat, Raspberry Pi,

\section{PENDAhUluan}

Pintu pagar merupakan salah satu keamanan paling terdepan dalam menjaga suatu bangunan. Pintu pagar memiliki berbagai jenis dari jaman dahulu sampai sekarang dengan menggunakan kunci tambahan.[1]

Ilmu dan teknologi pengolahan citra merupakan suatu ilmu yang bermanfaat dalam kehidupan. Pengolahan citra merupakan pemrosesan gambar melalui komputer untuk mendapatkan informasi tertentu. Salah satu penerapan pengolahan citra ialah pengenalan dan pendeteksian nomor plat kendaraan atau biasa dikenal License Plate Recognition (LPR).Di Indonesia masih kurang pengembangan dan penerapan ilmu tersebut pada kehidupan sehari-hari. Padahal dengan menerapkan LPR aktifitas seperti pengecekan identitas kendaraan ataupun pembatasan suatu area parkir dapat lebih dipermudah dan lebih otomatis[2].

ALPR banyak digunakan untuk mendeteksi mobil yang melanggar batas kecepatan, mengendalikan keamanan di area terlarang, manajemen parkir otomatis, penegakan hukum lalu lintas, dan pengelolaan jalan tol secara elektronis[3].

Seiring perkembangan waktu dan teknologi, palang dibuat agar dapat membuka dan menutup secara otomatis dengan tujuan dapat mempermudah kegiatan masuk dan keluarnya kendaraan. Pada penelitian ini akan dibuat sistem otomatisasi palang dengan pengenalan plat nomor kendaraan yang berfungsi sebagai kemudahan dalam proses pembatasan lahan parkir. Kelebihan dari sistem ini terletak pada sistem pengenalan plat nomor kendaraan yang dirancang lebih efisien dan sederhana dalam mengenali plat yang sudah didata sebelumnya.

Dengan adanya pintu otomatis ini, dapat memudahkan dalam membuka dan menutup tanpa bersusah payah mendorong ataupun menggeser pintu pagar. Selain itu dengan maraknya pencurian memerlukan sistem keamanan yang memerlukan tingkat keamanan yang tinggi.[4]

\section{Metodologi PENELITIAN}

Kerangka Penelitian

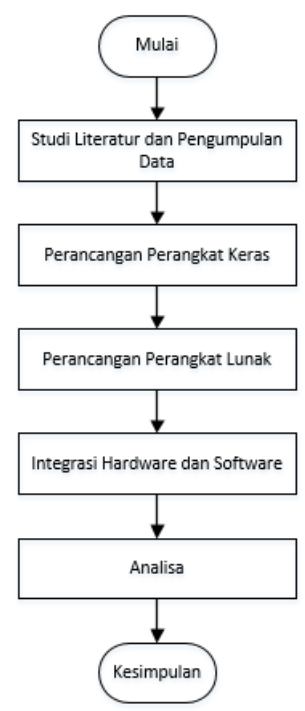

Gambar 1. Kerangka Penelitian 
Dari gambar diatas, dapat dilihat bahwa tahapan penelitian dimulai dari tahapan tahapan sebagai berikut :

1. Studi Literatur dan Pengumpulan Data

Pada tahapan ini penulis mempelajari dan membaca arsip jurnal, literatur pustaka yang relevan dengan masalah yag akan dibahas. Studi literatur dilakukan dengan menelusuri sumber sumber penelitian sebelumya, baik dari buku, jurnal terakreditasi maupun internet. Pada tahap ini diketahui masalah pada pembatasan lahan parkir yang semakin lama semakin sedkit lahan yang tersedia. Maka dari itu, studi literatur dapat dilakukan pembaharuan untuk penelitian lebih lanjut.

2. Perancangan Perangkat Keras

Perancangan perangkat keras diawali dengan pembuatan blok diagram rangkaian. Pada penelitian ini terdapat komponen dan peralatan yang dibutuhkan seperti Arduino, Kamera sebagai pengambil gambar plat kendaraan, raspberry pi sebagai pengolah data yang diambil sebagai pembaca karakter plat kendaraan, dan motor servo sebagai penggerak palang untuk membuka dan menutup.

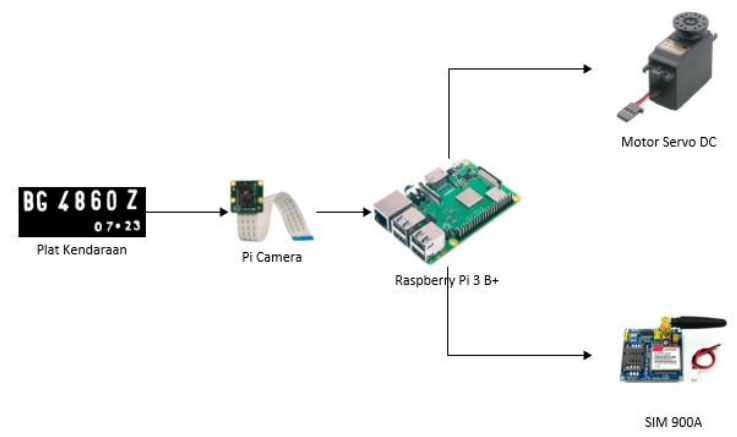

Gambar 2. Perancangan Perangkat Keras

3. Perancangan Perangkat Lunak

Setelah tahap komponen perangkat dirangkai serta dirakit, akan dilakukan proses perancangan perangkat lunak yaitu menggunakan aplikasi putty yang akan menampilkan hasil dan selanjutnya hasil pembacaan karakter yang telah didapat dari kamera akan diproses ke tahap selanjutnya.

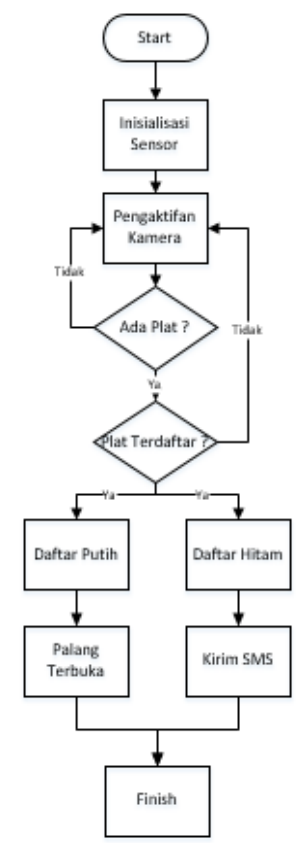

Gambar 3. Perancangan Perangkat Lunak

4. Integrasi hardware dan software

Tahap ini merupakan tahap dimana penulis menghubungkan elemen elemen dari sistem yaitu hardware dan software sehingga dapat bekerja sesuai dengan harapan.

5. Analisa

Tahap ini penulis akan melakukan analisa atau mengkaji alat yang telah dibuat

6. Kesimpulan

Tahap ini penulis akan merangkum semua aspek yang ada pada penelitian dan menyimpulkannya secara singkat, padat dan jelas.

\section{HASIL DAN PEMBAHASAN}

A. Desain Hardware

Perancangan hardware sistem palang otomatis yang telah berhasil dibuat berdasarkan rancangan alat. Sistem palang otomatis ini dibuat untuk membantu pengelolaan lahan sebagai tempat parkir. Hasil perancangan perangkat keras dapat dilihat pada gambar dibawah. 


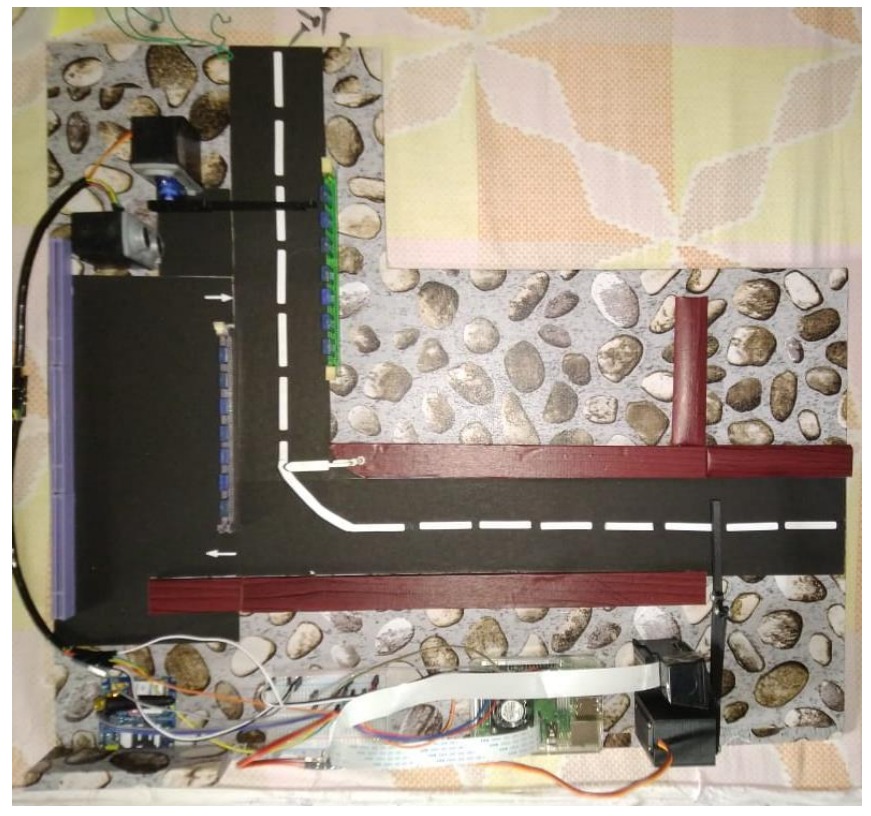

Gambar 4. Hasil desain hardware tampak atas

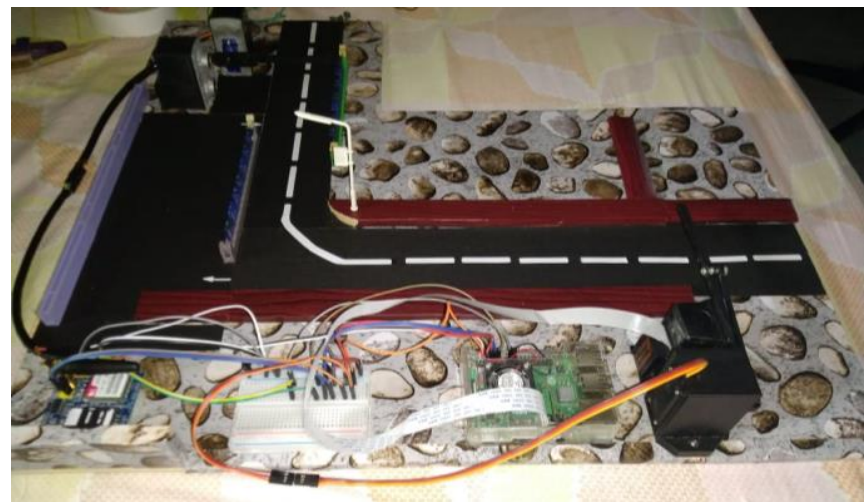

Gambar 5. Hasil desain hardware tampak samping

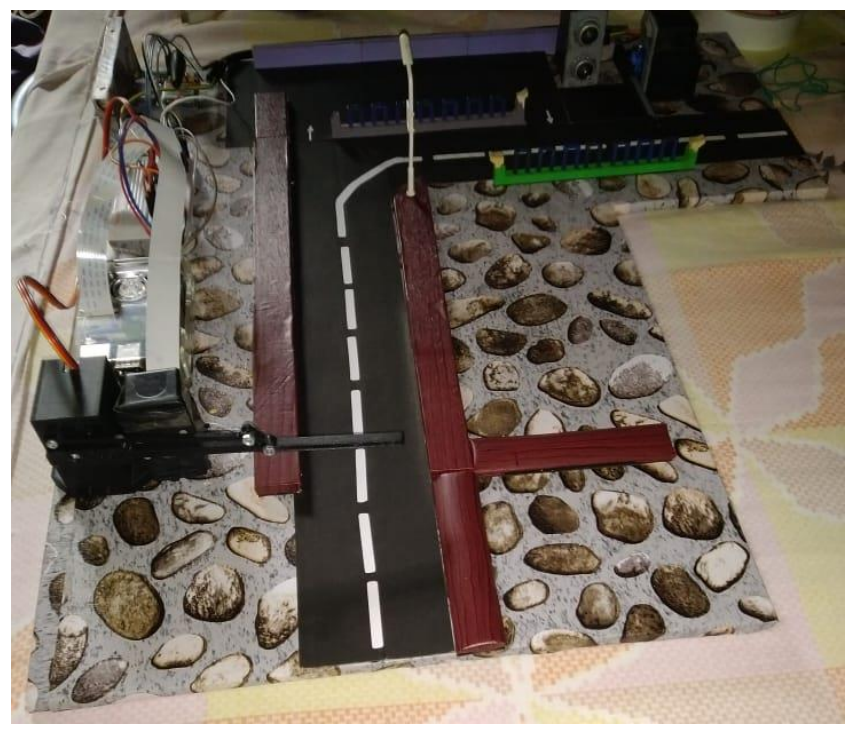

Gambar 6. Hasil desain hardware tampak depan

\section{B. Desain Software}

Perancangan perangkat lunak berhasil dibuat sesuai dengan perancangan awal. Software yang digunakan adalah putty. Putty berfungsi sebagai remote access yang digunakan untuk mengakses Command Line Interface (CLI) dari raspberry pi sehingga dapat dikonfigurasi. Hasil pembacaan plat dari kamera akan diproses di raspberry pi dan ditampilkan di software putty.

$$
\begin{aligned}
& \text { [ WARN:0] global/build/opency } \\
& r . c p p(480) \text { isPipelinePlaying } \\
& \text { ve not been created } \\
& \text { Done! } \\
& \text { Plate \#1 } \\
& \text { - BG5000IN } 85.482834 \\
& \text { Ada Nih } \\
& \text { BG50001N } 85.214874 \\
& \text { BG5000IM } 84.302429 \\
& \text { BG5000N } 84.162384 \\
& \text { BG50001M } 84.034470 \\
& \text { BG5000I } 83.428993 \\
& \text { BG5000IH } 83.228119 \\
& \text { BG50001 } 83.161026 \\
& \text { BG5000M } 82.981979 \\
& \text { BG50001H } 82.960159 \\
& \text { BG5000KN } 81.930725 \\
& \text { BG5000H } 81.9307669 \\
& \text { BG50001R } 81.702820 \\
& \text { G5000IN } 81.599472 \\
& \text { BG5000RN } 81.448166 \\
& \text { G50001N } 81.331512 \\
& \text { BG5000XN } 81.274353 \\
& \begin{array}{ll}
\text { BG5000KM } & 80.750320 \\
\text { BG5000R } & 80.650330
\end{array} \\
& \text { Measured Distance }=11.2 \mathrm{~cm}
\end{aligned}
$$

Gambar 7. Tampilan sistem saat mendeteksi plat dari daftar putih

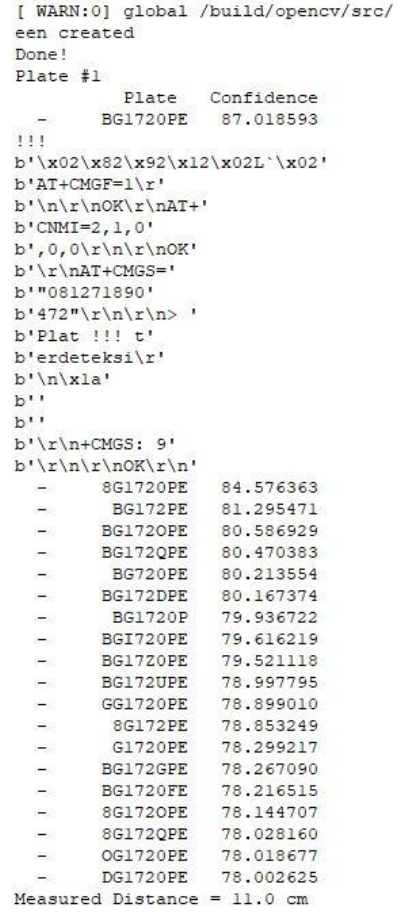

Gambar 8. Tampilan sistem saat mendeteksi plat dari daftar hitam 


\section{Pengujian}

Pengujian dilakukan dengan tujuan mengetahui kinerja dari sistem palang otomatis ini.

Tabel 1. Pengujian pada alat

\begin{tabular}{|c|l|l|l|l|}
\hline No. & Bank Parkir & Deteksi & $\begin{array}{c}\text { Hasil } \\
\text { Deteksi }\end{array}$ & Sistem \\
\hline 1. & BG2608ACC & BG2608ACC & Masuk & $\begin{array}{l}\text { Daftar } \\
\text { Putih }\end{array}$ \\
\hline 2. & BG2942UM & BG2942UM & Masuk & $\begin{array}{l}\text { Daftar } \\
\text { Putih }\end{array}$ \\
\hline 3. & BG4860Z & BG4860Z & Masuk & $\begin{array}{l}\text { Daftar } \\
\text { Putih }\end{array}$ \\
\hline 4. & BG5000IN & BG5000IN & Masuk & $\begin{array}{l}\text { Daftar } \\
\text { Putih }\end{array}$ \\
\hline 5. & BG5394AAG & BG5394AAG & $\begin{array}{l}\text { Tidak } \\
\text { Masuk }\end{array}$ & $\begin{array}{l}\text { Daftar } \\
\text { Hitam }\end{array}$ \\
\hline 6. & BG1720PE & BG1720PE & $\begin{array}{l}\text { Tidak } \\
\text { Masuk }\end{array}$ & $\begin{array}{l}\text { Daftar } \\
\text { Hitam }\end{array}$ \\
\hline 7. & BG6805ZY & BG6805ZY & $\begin{array}{l}\text { Tidak } \\
\text { Masuk }\end{array}$ & $\begin{array}{l}\text { Daftar } \\
\text { Hitam }\end{array}$ \\
\hline
\end{tabular}

\section{KESIMPULAN}

Berdasarkan penelitian yang telah dilakukan dan pembahasan yang telah diuraikan, maka dapat disimpulkan bahwa sistem dapat mendeteksi hasil dari kamera yang mengambi data berupa gambar dari plat yang kemudian dideteksi sebagai karakter. Plat yang masuk kedalam daftar putih sistem dapat mengakses parkir yang ada, sedangkan jika sistem mendeteksi plat yang masuk kedalam daftar hitam mencba masuk maka sistem akan mengirimkan notifikasi berupa SMS ke penjaga. Jika sistem mendeteksi plat yang tidak terdaftar, maka sistem tidak akan melakukan apa apa dan beroperasi seperti semula sampai ada plat yang masuk kedalam sistem. Dari 7 percobaan plat yang dilakukan, sistem berhasil mendeteksi 4 plat yang dapat masuk ke dalam parkir. Hal itu dikarenakan 4 plat tersebut merupakan plat yang terdaftar ke dalam daftar putih di sistem parkir yang telah dibuat, dan 3 plat merupakan plat yang masuk ke dalam daftar hitam sistem.

\section{UCAPAN TERIMA KASIH}

Penulis menyampaikan rasa terimakasih yang sebesar besarnya dan penghargaan setinggi tingginya kepada bapak Dr. Dipl. Ing. Ahmad Taqwa. M.T. dan bapak Ir. Jon Endri., M.T. selaku dosen pembimbing yang disela sela waktu dan kesibukannya tetap dapat meluangkan waktu untuk memberikan masukan dan saran sehingga selesainya penelitian ini.

\section{DAFTAR ACUAN}

[1] Yogie el Anwar, Noer Soedjarwanto, Ageng Sadwono Repelianto.2015 'Prototype Penggerak Pintu Pagar Otomatis Berbasis Arduino Uno ATMEGA 328P dengan Sensor Sidik Jari'

[2] Dendi Triyandi, Jhon Adler. 2017 "SISTEM OTOMATISASI GERBANG DENGAN PENGOLAHAN CITRA MEMBACA NOMOR PLAT KENDARAAN"

[3] Bagade, J.V., Kamble, M.S., Pardeshi, K., Punjabi, B., Singh, R., 2013, "Automatic Number Plate Recognition System: Machine Learning Approach", IOSR Journal of Computer Engineering, Vol. 1, Special Issue Second International Conference on Emerging Trends in Engineering, pp. 34-39

[4] Ashar Seppiawan N, Nurussa'adah. 2013 'SISTEM KEAMANAN PINTU PAGAR OTOMATIS MENGGUNAKAN VOICE RECOGNITION' 